Article

\title{
Complex Dynamics Induced by Nonlinear Pollution Absorption, Pollution Emission Rate and Effectiveness of Abatement Technology in an OLG Model
}

\author{
Dong Cao ${ }^{1,2, *}$, Lin Wang ${ }^{3}$ and Shouyang Wang ${ }^{2}$ \\ 1 School of Economics and Management, Xidian University, Xi'an 710071, China \\ 2 Academy of Mathematics and Systems Science, China Academy of Sciences, Beijing 100190, China; \\ sywang@amss.ac.cn \\ 3 Department of Mathematics and Statistics, University of New Brunswick, Fredericton, NB E3B5A3, Canada; \\ lwang2@unb.ca \\ * Correspondence: ivycaodong@163.com; Tel.: +86-29-8189-1360
}

Academic Editor: Marc Rosen

Received: 8 March 2017; Accepted: 1 May 2017; Published: 4 May 2017

\begin{abstract}
In this work, nonlinear pollution absorption, emission rate, and effectiveness of abatement technology are incorporated into the classic overlapping generation model. Within this framework, we analyze the macroeconomic effects of pollution emission and abatement technology on the economy. Our findings reveal that different levels of pollution emission rates from per capita income and the effectiveness of abatement technology could induce complex dynamical behavior, including the occurrence of a stable equilibrium, cycles, and chaos. Our analysis shows that either the pollution emission rate per capita income should be controlled to be small enough or the effectiveness of abatement technology should be large enough to maintain a stable system yielding high level of per capita income. A high level of pollution emission rate per capita income and a low level of effectiveness of abatement technology can lead to a stable economy, but with a low level of per capita income. In the case that the pollution emission rate and the effectiveness of abatement technology vary in a certain range, the economy would become unstable, and cycles and chaos would emerge.
\end{abstract}

Keywords: pollution absorption; pollution emission; abatement technology; OLG model

\section{Introduction}

Environmental pollution has become a serious societal issue [1-4]. Pollution stock accumulation problems due to pesticide resistance, soil erosion, water pollution, and climate change have attracted more and more attention in studies of economic growth [5].

Though fossil fuel provides the power needed in production and greatly increases consumption levels, the negative energy externality can no longer be ignored. Burning of fossil fuels generates sulfuric, carbonic, and nitric acids, which produce extreme harm to the environment. Combustion of fossil fuels releases radioactive materials such as uranium and thorium, and generates a large amount of bottom ash and fly ash. In addition, the harvesting, processing, and distribution of fossil fuels cause many environmental concerns. Aside from pollution generated from the use of fossil fuels, most human activities-especially during the production process-also emit pollution. Some pollution can be absorbed by the environment, but as nature's capacity to absorb pollution is limited, most pollution tends to accumulate in the surrounding environment and has very long residence time, lasting from decades to centuries. High pollution concentration causes enormous human health problems and environmental deterioration. It remains uncertain for the growth of output over the next century and beyond, for what energy systems will be developed in the decades ahead, for 
the pace of technological changes in substitutes for pollution materials used or in pollution-removal technologies, for the reaction to rising pollution in the environment, and perhaps most of all about the economic and ecological responses to a changing environment [6]. This makes it very difficult to identify the real amount of pollution stock. Broadly speaking, the real amount of pollution stock is affected by the environmental absorption capacity, the emission of economic output, and the abatement technologies.

The environment has the ability to absorb pollution. For example, many plants have the ability to gradually remove toxins from air, water, and soil. The forest and ocean have the ability to be a carbon sink. The microorganisms in the earth and ocean also have the capability to absorb the pollutants-a process called bio-remediation. However, the environment's ability to act as a sink for pollutants is limited by the scarcity of natural resources. The bounded absorption capability of pollution by the environment and the necessity for economic activity to comply with environmental limits have been noticed. For example, Ouardighi and Benchekroun [7] proposed a pollution accumulation model with environmental absorption capacity in which the environmental absorption capacity is shown to be impacted by economic activity. Zemel [8] pointed out that the natural decay of the pollution stock is a stochastic process. It is argued that the environment possesses nonlinear absorption capacity rather than a constant or linear one [9,10]. Canadell [9] found a decline in the efficiency of $\mathrm{CO}_{2}$ sinks in the last 50 years and largely increased the carbon intensity. A similar trend has been observed with other pollutants [5]. If gas concentrations are too high, then there is a nonlinear absorption [10]. Endo et al. [11] found that the removal of extractable organic material causes the sorption of soot-considered as an important sorbent for organic contaminants in soils, sediments, and aerosols-to be more nonlinear and with a decreasing trend. However, most of the existing work has ignored the nonlinear environmental absorption capacity. Consequently, this may make the dynamic behavior of pollution accumulation misleading in understanding the economy [12].

In this paper, we aim to capture the macroeconomic effects of pollution emission and abatement varieties on an overlapping generation (OLG) economy with nonlinear environment pollution absorption. We point out that in optimal economic growth literature, pollution is always considered as an emission and by-product of economic growth, and has a negative effect on the utility agents. Gutierres [13] analyzed the effects that pollution can produce on the economy when it affects the health of agents who are forced to spend on medical care when they are elderly. Most of the existing literature focuses on the emission effect of economic growth. Hofer et al. [14] studied the direct effect of pollution on the production function. Ang [15] examined the dynamic relationships between output, $\mathrm{CO}_{2}$ emissions, and energy consumption in Malaysia during the period 1971-1999 using a multivariate vector error-correction model. Poumanyvong and Kaneko [16] conducted an empirical investigation of the effect of urbanization on energy use and $\mathrm{CO}_{2}$ emissions with consideration of different development stages. Duarte et al. [17] analyzed the relationship between per capita water use and per capita income for 65 countries over the period 1962-2008, within the framework of the Kuznets curve.

Recently, increasing attention has been paid by governments, international organizations, and academics to abatement technologies and investment in new technologies via taxes, fiscal policy, and environmental regulation. Heijdra et al. [18] introduced the idea that abatement and tax can be used to reduce the inflow of dirt and bring down the stock of the polluting capital input. Dam [19] studied an OLG model with stock market allowing agents to choose between investing in "clean" government bonds and polluting firm equity, and showed that stock prices can help solve the pollution cost conflicts between current and future generations. Others tried to estimate the marginal abatement cost of pollutants-especially green house gas [20,21]. Du et al. [20] calculated a quadratic parameterized directional output distance function, and concluded that the shadow price of $\mathrm{CO}_{2}$ abatement in China increased from $¥ 1000 /$ ton in 2001 to $¥ 2100$ /ton in 2010. The incremental pollutant abatement cost (PAC) of greenhouse gas reduction bill regulation on Taiwan's freeway bus service industry from 2008 
to 2010 was assessed in [21], and it has been calculated that the average incremental PAC during that period was NT $\$ 69.2$ million.

In this paper, we aim to analytically characterize the complex dynamics induced by the nonlinear pollution absorption process within an OLG economy. The basic OLG model is an excellent tool for studying phenomena depending on inter-generational transfers if one can assume that each retired generation consumes all of its savings or, equivalently, each new generation replaces the entire capital stock employed by the previous generation. For this purpose, nonlinear pollution absorption, emission rate, and effectiveness of abatement technology will be incorporated into the classic OLG model in this work.

We organized the rest of the paper as follows. We present our basic pollution stock model in Section 2 and study its dynamics in Section 3. Related economy and policy implications from our findings are presented in Section 4. We conclude our paper in Section 5 with a brief summary and discussion.

\section{The Basic Pollution Stock Model}

An OLG economy is considered throughout this paper. Thus, two overlapping generations of consumers (the young and the old) with constant populations (normalized to one) are assumed at each period $t \in\{0,1, \cdots, \infty\}$. At period $t$, a representative young individual works supplying one unit of labor inelastically and retires when he becomes old at period $t+1$ and rents his savings to firms earning the gross return at the rate of $1+r_{t+1}-\delta$, where $r_{t+1}$ and $\delta \in[0,1]$ represent the interest rate and the depreciation rate of capital, respectively. As in [1,3], we assume that a representative individual derives utility only in old age, from consumption $C_{t+1}$ and the quality of the environment. Here we assume that the quality of the environment decreases as the accumulation of pollution $P_{t+1}$ increases, where $P_{t+1}$ represents the additional concentration of pollution such as green house gas like $\mathrm{CO}_{2}$ with respect to its pre-industrial level. The utility function $U\left(C_{t+1}, P_{t+1}\right)$ is assumed to take the following form

$$
U\left(C_{t+1}, P_{t+1}\right)=C_{t+1}-\frac{P_{t+1}^{2}}{2 B},
$$

where $B>0$ is a scaling parameter [22]. To have a good quality of environment in old age, a representative young consumer invests a portion of her income, $d_{t}$, in pollution abatement. This leaves the rest of her income, $s_{t}=w_{t}-d_{t}$, as her savings for old-age consumption. Thus, her budget constraints are given by

$$
w_{t}=d_{t}+s_{t}, \text { and } C_{t+1}=\left(1+r_{t+1}-\delta\right) s_{t} .
$$

If full depreciation over one period is assumed, then $\delta=1$, and the second equation in (2) becomes $C_{t+1}=r_{t+1} s_{t}$.

As in [3], we use the following equation to describe the evolution of $P_{t+1}$

$$
P_{t+1}=(1-m) P_{t}+e k_{t}-b d_{t}
$$

where $m$ is the natural pollution absorption rate, $e>0$ is the emission rate of pollution from per capita income, and $b>0$ denotes the effectiveness of abatement technology. In the environmental economic modeling literature (e.g., [1,3,4]), $m$ is assumed to be a constant. However, the most recent research results show that the environmental absorption capacity is not a constant, but has some nonlinear characteristics (see $[5,10,11]$ ). It is reasonable to assume that when the pollution stock level is relatively low, the environment may have a relatively high absorption capacity, while it may not be valid when the pollution accumulations become too high. In the extreme case, as $P_{t}$ becomes sufficiently 
large, the carbon sinks would cease functioning and thus $m$ would become zero. Based on the above argument, in this work, we assume that $m=m\left(P_{t}\right)$ is decreasing in $P_{t}$ taking the following form

$$
m=m\left(P_{t}\right)=\frac{a}{1+a_{1} P_{t}}, \text { where } a \in[0,1], a_{1}>0 .
$$

Thus, (3) becomes

$$
P_{t+1}=\left(1-\frac{a}{1+a_{1} P_{t}}\right) P_{t}+e k_{t}-b d_{t} .
$$

The problem facing the representative agent is then given by

$$
\begin{aligned}
& \max U\left(C_{t+1}, P_{t+1}\right) \\
& \text { s.t. }\left\{\begin{array}{l}
w_{t}=s_{t}+d_{t} \\
C_{t+1}=r_{t+1} s_{t} \\
P_{t+1}=\left(1-\frac{a}{1+a_{1} P_{t}}\right) P_{t}+e k_{t}-b d_{t} .
\end{array}\right.
\end{aligned}
$$

Since the final good is assumed to be produced by the representative firm with a constant return to scale technology, we can express the output per worker in the form of

$$
y_{t}=f\left(k_{t}\right),
$$

where $k_{t}$ is capital-labor ratio and the production function $f$ satisfies

$$
f^{\prime}\left(k_{t}\right)>0 \text { and } f^{\prime \prime}\left(k_{t}\right)<0 \text { for } k_{t}>0 .
$$

We also assume the Inada conditions

$$
f^{\prime}(0)=\infty \text { and } f^{\prime}(\infty)=0
$$

hold. These conditions imply that the marginal product of capital approaches infinity at zero capital and decreases to zero when the capital becomes infinitely large. The firm maximizes its profit in a competitive clearing market. Thus, we have the following standard equations

$$
r_{t+1}=f^{\prime}\left(k_{t+1}\right), w_{t}=f\left(k_{t}\right)-k_{t} f^{\prime}\left(k_{t}\right) .
$$

Moreover, to get the capital market equilibrium, it is required that

$$
s_{t}=k_{t+1}
$$

which means the total saving in period $t$ equals the capital demand in period $t+1$.

\section{Dynamics of the Economy}

\subsection{Equilibrium: Existence and Uniqueness}

For the utility function given in (1), it follows from the first condition of the representative agent's maximization problem with respect to $d_{t}$ that

$$
r_{t+1}=\frac{P_{t+1}}{B_{1}}
$$


where $B_{1}=\frac{B}{b}$. Equation (12) captures effect of pollution on interest rate and the price of capital use. Substituting the first budget constraint in (6) and the first-order condition (12) into (5) leads to the following difference equation

$$
B_{1} f^{\prime}\left(k_{t+1}\right)=B_{1} f^{\prime}\left(k_{t}\right)-\frac{a B_{1} f^{\prime}\left(k_{t}\right)}{1+a_{1} B_{1} f^{\prime}\left(k_{t}\right)}+e k_{t}-b f\left(k_{t}\right)+b k_{t} f^{\prime}\left(k_{t}\right)+b k_{t+1} .
$$

Proposition 1. Equation (13) implicitly defines a nonlinear map, $G: \mathbb{R}_{+} \rightarrow \mathbb{R}_{+}$with $k_{t+1}=G\left(k_{t}\right)$; that is, for any given $k_{t}>0$, there exists a unique $k_{t+1}>0$ that satisfies (13).

Proof. Denote the left-hand-side of (13) by $H_{1}\left(k_{t+1}\right)$, then it follows from (8) and (9) that the function $H_{1}(u)$ is decreasing for $u>0$, with

$$
\lim _{u \rightarrow 0} H_{1}(u)=\infty \text { and } \lim _{u \rightarrow \infty} H_{1}(u)=0 .
$$

Once $k_{t}>0$ is given, then the right-hand-side of (13) can be regarded as a function of the unknown $k_{t+1}$, which we denote by $H_{2}\left(k_{t+1}\right)$. Clearly, the function $H_{2}(u)$ is increasing in $u$, with

$$
\lim _{u \rightarrow 0} H_{2}(u)=B_{1} f^{\prime}(0)-\frac{a B_{1} f^{\prime}(0)}{1+a_{1} B_{1} f^{\prime}(0)}-b f(0)<\lim _{u \rightarrow 0} H_{1}(0)=B_{1} f^{\prime}(0)=\infty,
$$

and

$$
\lim _{u \rightarrow \infty} H_{2}(u)=\infty>\lim _{u \rightarrow \infty} H_{1}(u)=0 .
$$

Therefore, there must exist a unique $k_{t+1}>0$ such that (13) is satisfied. The proof is complete.

The perfect foresight equilibrium is a sequence $\left\{k_{t}, t=0,1,2, \ldots\right\}$ that satisfies (13). An equilibrium of (13) is a level $k$ such that

$$
B_{1} f^{\prime}(k)=B_{1} f^{\prime}(k)-\frac{a B_{1} f^{\prime}(k)}{1+a_{1} B_{1} f^{\prime}(k)}+e k-b\left[f(k)-k f^{\prime}(k)-k\right],
$$

which can be simplified as

$$
\frac{a B_{1} f^{\prime}(k)}{1+a_{1} B_{1} f^{\prime}(k)}=(b+e) k-b f(k)+b k f^{\prime}(k) .
$$

Let

$$
F_{1}(k)=\frac{a B_{1} f^{\prime}(k)}{1+a_{1} B_{1} f^{\prime}(k)}
$$

and

$$
F_{2}(k)=(b+e) k-b f(k)+b k f^{\prime}(k),
$$

then $F_{1}^{\prime}(k)=\frac{a B_{1} f^{\prime \prime}(k)}{\left(1+a_{1} B_{1} f^{\prime}(k)\right)^{2}}<0$. By (9), we have

$$
\lim _{k \rightarrow 0} F_{1}(k)=\lim _{k \rightarrow 0} \frac{a B_{1} f^{\prime}(k)}{1+a_{1} B_{1} f^{\prime}(k)}=\frac{a}{a_{1}}>0, \text { and } \lim _{k \rightarrow \infty} F_{1}(k)=0 .
$$

We further assume that

$$
\lim _{k \rightarrow 0} k f^{\prime}(k)=0, \lim _{k \rightarrow 0} k f^{\prime \prime}(k)=-\infty, \lim _{k \rightarrow \infty} k f^{\prime \prime}(k)=0,
$$

and

$$
k f^{\prime \prime \prime}(k)+f^{\prime \prime}(k)>0 \text { for } k>0, \lim _{k \rightarrow \infty} \frac{f(k)}{k}=0 .
$$


It follows from (16) and (18) that

$$
\lim _{k \rightarrow 0} F_{2}(k)=0 \text { and } \lim _{k \rightarrow \infty} F_{2}(k)=\infty .
$$

Note that $F_{2}^{\prime}(k)=b+e+b k f^{\prime \prime}(k)$ and $F_{2}^{\prime \prime}(k)=b\left(f^{\prime \prime}(k)+k f^{\prime \prime \prime}(k)\right)$. This, together with (18) and (19), shows that $F_{2}^{\prime}(k)$ is increasing for $k>0$ and

$$
\lim _{k \rightarrow 0} F_{2}^{\prime}(k)<0, \lim _{k \rightarrow \infty} F_{2}^{\prime}(k)=b+e>0 .
$$

Using the continuity of $F_{2}$, there must exist a $\bar{k}>0$ satisfying $F_{2}^{\prime}(\bar{k})=0$ such that $F_{2}(k)$ is increasing for $k \in(\bar{k}, \infty)$ and is decreasing for $k \in(0, \bar{k})$. Note that $F_{1}(k)>0$ and $F_{2}(k)<0$ for $k \in(0, \bar{k})$, the equation $F_{1}(k)=F_{2}(k)$ has no solution in the interval $(0, \bar{k})$. On the other hand, since $F_{1}(\bar{k})-F_{2}(\bar{k})>0, F_{1}(\infty)-F_{2}(\infty)=-\infty$ and $F_{1}(k)-F_{2}(k)$ is a decreasing function of $k$ for $k>\bar{k}$, there must exist a unique $k^{*} \in(\bar{k}, \infty)$ satisfying $F_{1}\left(k^{*}\right)=F_{2}\left(k^{*}\right)$. A numerical sketch of the above argument is demonstrated in Figure 1.

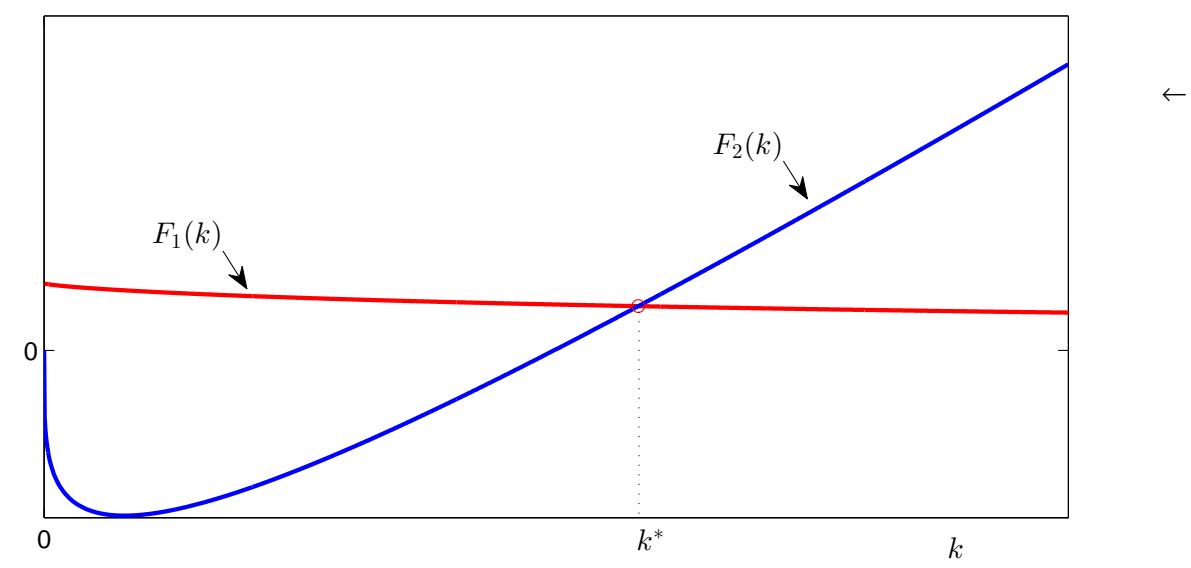

Figure 1. Determination of the unique equilibrium.

Summarizing the above discussion, we have the following proposition.

Proposition 2. Under the assumptions (18) and (19), Model (13) admits a unique positive equilibrium $k^{*}$ satisfying

$$
k^{*}=G\left(k^{*}\right)
$$

Taking the total differential of (13), we can get

$$
\frac{\partial k_{t+1}}{\partial k_{t}}=\frac{\frac{\left[B_{1}+a_{1} B_{1}^{2} f^{\prime \prime}\left(k_{t}\right)-a B_{1}\right] f^{\prime \prime}\left(k_{t}\right)}{1+a_{1} B_{1} f^{\prime}\left(k_{t}\right)}+e+b k_{t} f^{\prime \prime}\left(k_{t}\right)}{B_{1} f^{\prime \prime}\left(k_{t+1}\right)-b} .
$$

Then we evaluate all derivatives at the equilibrium $k^{*}$ to obtain

$$
G_{k}^{\prime}=\frac{\frac{\left[B_{1}+a_{1} B_{1}^{2} f^{\prime \prime}\left(k^{*}\right)-a B_{1}\right] f^{\prime \prime}\left(k^{*}\right)}{1+a_{1} B_{1} f^{\prime}\left(k^{*}\right)}+e+b k^{*} f^{\prime \prime}\left(k^{*}\right)}{B_{1} f^{\prime \prime}\left(k^{*}\right)-b} .
$$

However, the relationship between $\left|G_{k}^{\prime}\right|$ and 1 is unclear, and the equilibrium $k^{*}$ may be stable or unstable. In addition, periodic cycles may appear. Furthermore, as the parameters vary, there may be bifurcations including flip bifurcations leading to chaos. We numerically explore this in the next subsection. 


\subsection{Complex Dynamics}

Note that the nonlinear map $G$ is not explicitly given, but is rather defined implicitly by (13); it is very difficult to analyze the dynamics of the map $G$ analytically. In this section, we numerically explore the emergence of complex dynamics. To illustrate this, we take the production function $f$ as the widely-adopted Cobb-Douglas function

$$
f=A k^{\theta},
$$

where $A>0$ is the level of the technology and $\theta \in(0,1)$ is the per capita output elasticities. These values are constants determined by the available technology.

Assumptions (18) and (19) can be easily verified, and hence the map $G$ is well defined and there exists a unique positive equilibrium $k^{*}$. For numerical simulations, we take parameter values: $A=4$, $\theta=0.25, a=0.6, a_{1}=5$, and $B=0.025$.

We first fix $b=0.4$ and illustrate the macroeconomic effect of pollution emission rate, $e$, on the OLG economy in Figure 2. It is shown that if the rate of pollution emission rate $e$ is relatively low, then the system converges to an equilibrium with high level of per capita income. With the increase of pollution emission rate, the system becomes unstable. When $e$ is relatively high, the system regains its stability, but with a low level of per capita income $k$.

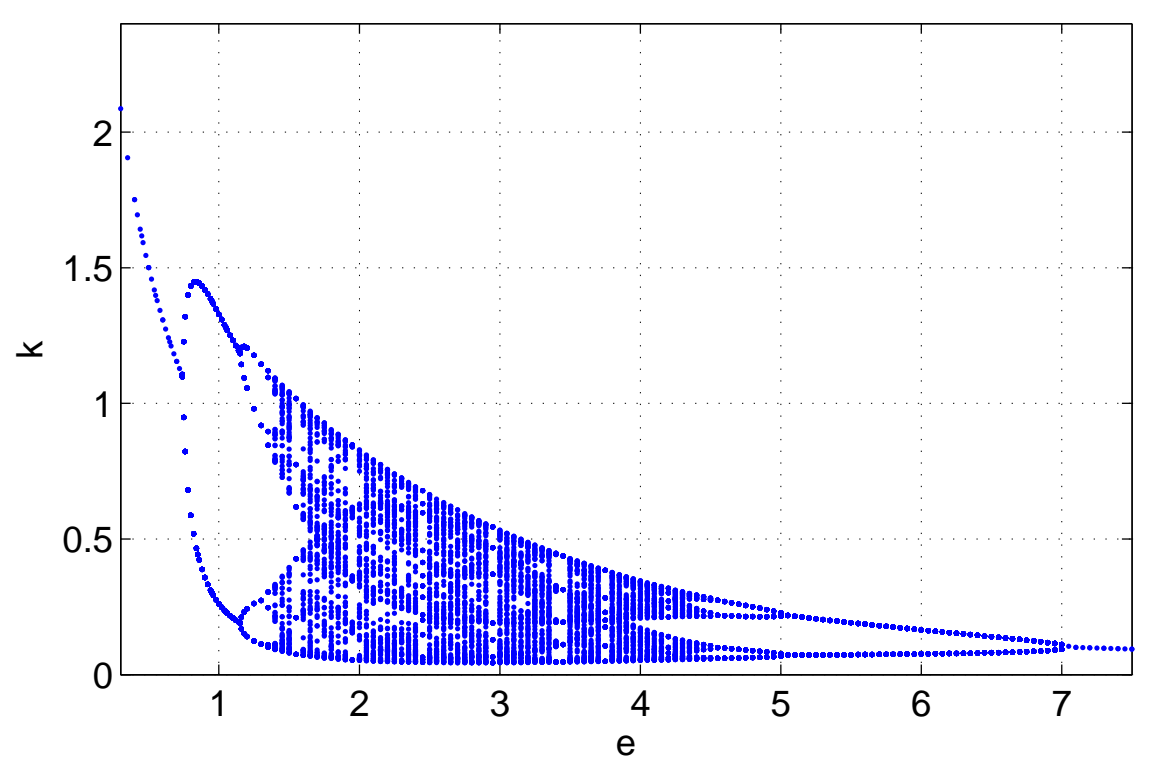

Figure 2. Bifurcation diagram with respect to emission rate $e$.

To demonstrate how the abatement technology affects the macro-economy, we fix $e=2.2$ and vary $b$ to obtain the bifurcation diagram in Figure 3. 


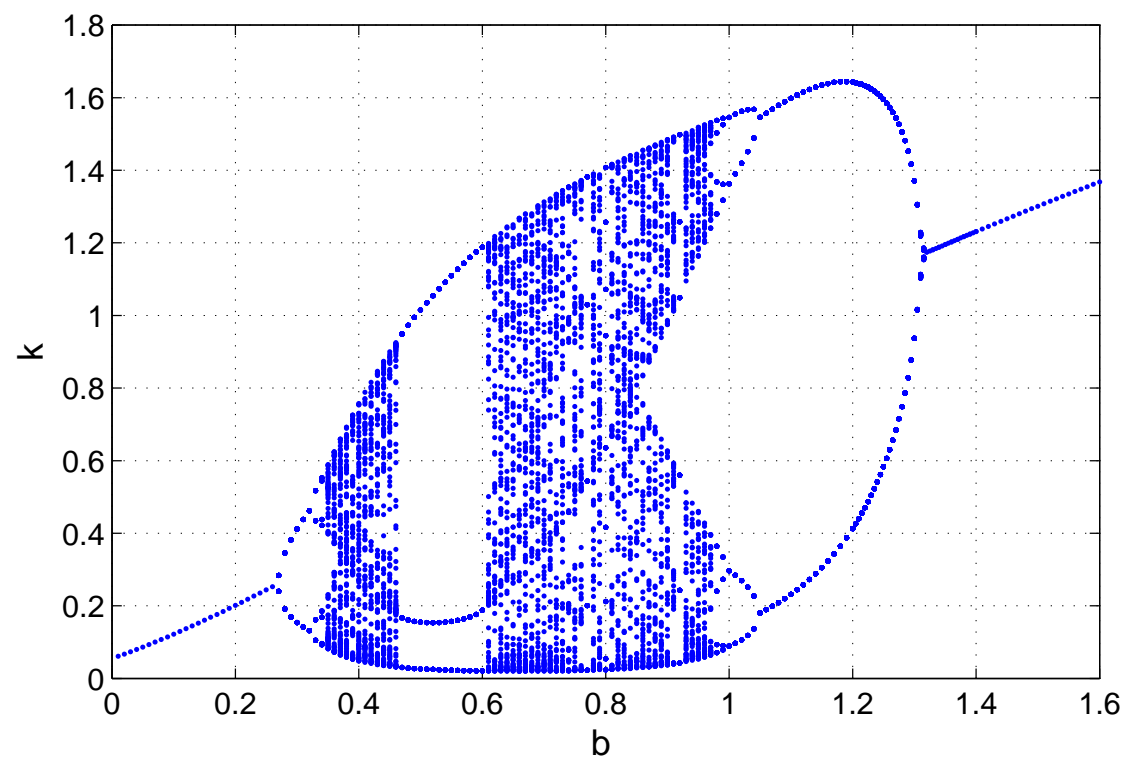

Figure 3. Bifurcation diagram with respect to the effectiveness of pollution abatement $b$.

As shown in Figure 3, the effectiveness of abatement technology $b$ could also lead to complex dynamic behaviors. If the effectiveness of abatement technology $b$ is relatively low, the system is stable with a low level of capital income. With the increase of the effectiveness of abatement technology $b$, the system may become unstable. When the effectiveness of pollution abatement technology $b$ is relatively high, the system becomes stable again with a high level of capital income.

To consider the combined effect of pollution emission and abatement technology, we obtain the stability region in the $e l-b$ space. A typical sketch is presented in Figure 4.

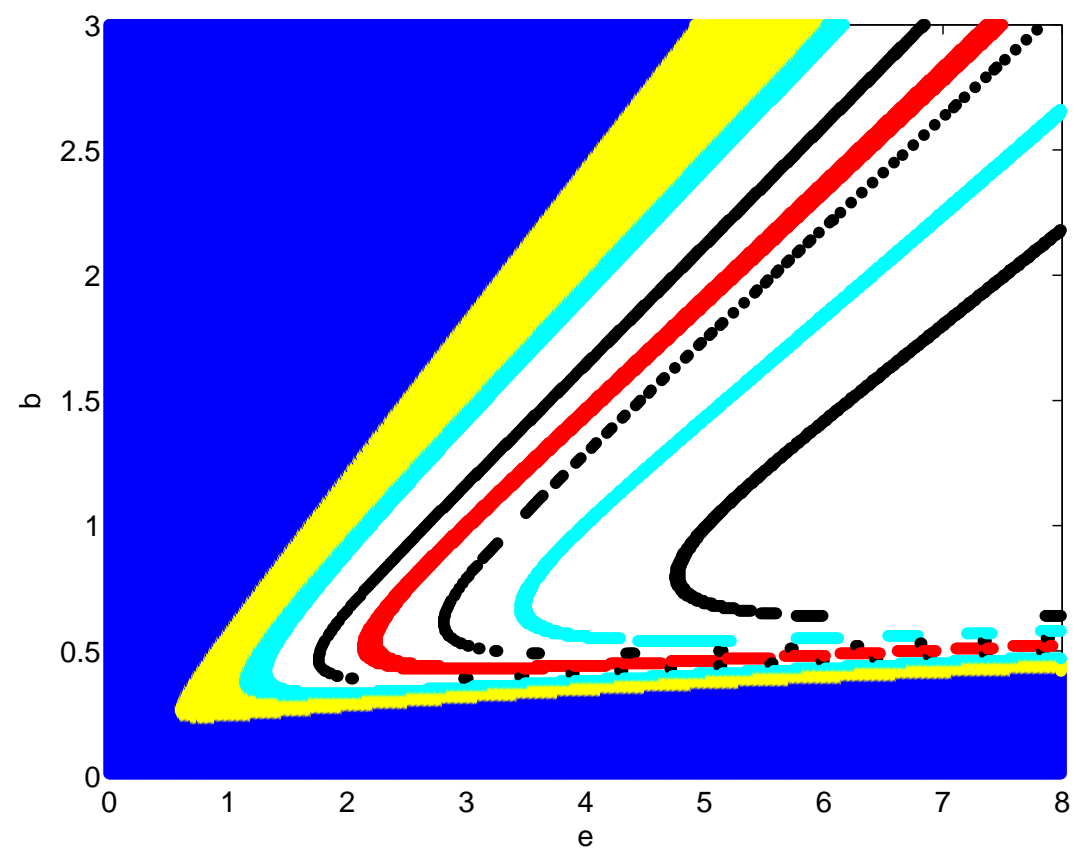

Figure 4. Stability region in the $e-b$ space (blue: stable equilibria; yellow: period-2 cycles; red: period-3 cycles; cyan: period-4 cycles; black: period-5 cycles; white: cycles with periods larger than 5). 
As shown in Figure 4, if the pollution emission rate from per capita income $e$ is relatively small, and the effectiveness of abatement technology $b$ is relatively high, the system is very likely to converge to a stable equilibrium with high level of capital income. On the other hand, if $e$ is relatively large and $b$ is relatively low, then the economy will sink to a stable equilibrium with a low level of capital income. For other ranges of $e$ and $b$ values, cycles and chaos may emerge. Hence, by investing more in improving the effectiveness of pollution abatement technology and controlling pollution emission, it is possible to achieve a stable state with high level of capital income and low pollution accumulation.

\section{Economy and Policy Implications}

Bifurcation diagrams presented in the previous section implicate that investment in production can have two opposite effects. On the one hand, production will bring wages to the individual, which is the source of consumption. On the other hand, the production process will cause pollution emission. The former has a positive effect on the utility function, and the latter has a negative effect on the utility function. When the emission rate of pollution from per capita income $e$ (the effectiveness of pollution abatement rate $b$ ) is relatively low, the representative individual knows she will suffer very little from the pollution emission, and the positive effects overcome the negative ones; therefore, she prefers to invest for higher per capita income. When the emission rate of pollution from per capita income $e$ (the effectiveness of pollution abatement rate $b$ ) is relatively high, the representative individual knows she will suffer a lot from the pollution emission, and the negative effects outweigh the positive one; therefore, she prefers to invest less and gets a low level of per capita income. If the value of $e(b)$ is between these critical values, then it becomes difficult for the agent to make a rational decision on his investment. Consequently, there arises fluctuations between per capita income (which is an unstable cobweb dynamics), and hence the capital income will undergo unstable fluctuations. These fluctuations in capital income will increase the aggregate regret in the following period. As a result, the same fluctuations will appear in the next period, leading to the emergence of endogenous fluctuation cycles.

It has been questioned from several aspects about the existence of the environmental Kuznets curve (EKC). Only certain air quality indicators-especially local pollutants-have illustrated the existence of an EKC. One reason mentioned in [23] is the neglect of emission of pollutants and institution reforms on pollution abatement technology. In contrast, in this work, by incorporating nonlinear environmental pollution absorption, the pollutant stock is shown to be determined both by pollution emission and the abatement technology. As the production has two opposite effects on utility and an individual does not know which effect is predominant, the economy would become unstable.

This theoretical contribution may find significant applications in the design and calibration of environmental policies. To avoid complex dynamics so that the economy approaches a sustainable equilibrium, much greener preferences and more efficient abatement technologies should be introduced. To achieve this, the following four possible policies might be implemented: (i) Reduce pollution emission rate by implementing firm regulations on pollutant emit firms, point and non-point pollution source, and cross-regional polluters; (ii) Increase pollution abatement efficiency by investing and promoting efficient pollution abatement technology; (iii) Develop and improve laws and regulations on pollution control; and (iv) Use economic means, such as pollution tax and emissions authority.

\section{Summary and Discussion}

In this work, we have proposed a new version of OLG model that incorporates nonlinear pollution absorption, pollution emission, and abatement technology. Within this framework, we analyzed the macroeconomic effects of the pollution emission rate from per capita income $e$ and the effectiveness of abatement technology $b$. We have shown that the nonlinear pollution absorption in the OLG model can induce complex dynamic behaviors yielding a stable equilibrium, cycles, and flip bifurcations and chaos. If the emission rate of pollution from per capita income $e$ (the effectiveness of abatement technology $b$ ) is lower (higher) than some critical value, the system is stable. With the increase of $e(b)$, 
the system may become unstable and cycles and even chaos may appear. When $e(b)$ is extremely high, the system becomes stable again but with low (high) level of capital income $k$.

From an economic point of view, our results indicate that on the one hand, the production process promotes higher wages and more consumption. On the other hand, production-associated pollution emission increases the pollution stock. The variations in pollution emission rate from per capita income $e$ and the effectiveness of abatement technology $b$ would make it extremely difficult for the agent to balance between these two aspects, and this leads to the fluctuations observed in the capital income. We have also analyzed the combined macroeconomic effects of pollution emission rate from per capita income $e$ and effectiveness of abatement technology $b$. The economy with relatively small $e$ combined with relatively high $b$ - or relatively large $e$ combined with relatively small $b$-is very likely to be stable. The former would sink to a high level of capital income, and the latter would lead to a low level of capital income. For certain combinations of $e$ and $b$, the economy would exhibit fluctuations.

As pointed out by [12], complex dynamic phenomena are very common in economic systems. For example, it is known that an OLG model is capable of inducing complex dynamics in economic systems [3]. Note that the endogenous dynamic behaviours presented in [3] occur when the pollution emission rate is in an unrealistic range and thus their results are not practicable in policy-making. It is not well-studied in systems with environmental pollution. Our work gives an attempt in this direction. Our main contribution to the pollution stock literature is that an analytical framework on the nonlinear pollution absorption process is established, which enables us to characterize the qualitative properties of the model. Our findings show that when a truly general form for nonlinear pollution absorption is considered in an economic growth system, a wide range of qualitative complex dynamics including stable equilibrium, cycles, and chaos can be induced by pollution emission and abatement. This theoretical contribution may provide practicable insights for environmental policy-making.

It is shown in [1] that cyclically or chaotically fluctuating equilibria are more likely to exist if people's concerns towards greener preferences and the maintenance efficiency relative to degradation are not sufficiently high. It is also pointed out in [4] that pollution perception-the difference between generations in the perceived level of pollutionversus the actual level of pollution-is also an important source of fluctuations in intergenerational equity. From these points of view, our work enriches the complex dynamics of OLG models by considering nonlinear pollution emission rate and abatement efficiency.

Acknowledgments: The authors would like to thank the referees for their comments and suggestions. This research is partially supported by grants from the National Natural Science Foundation of China (71303181) and the Science Foundation of Ministry of Education of China (11YJC790004), China Postdoctoral Science Foundation(2014M550864), the Fundamental Research Funds for the Central Universities of China(K50511060001, 7215566603), and Research Funds for Research Base of Modern Service Industry ofHunan Province(17SDCZD01).

Author Contributions: Dong Cao designed the research framework and wrote the first version of the manuscript; All authors jointly performed the analysis, simulations and revising the manuscript.

Conflicts of Interest: The authors declare no conflict of interest.

\section{References}

1. Zhang, J. Environmental sustainability, nonlinear dynamics and chaos. Econ. Theory 1999, 14, 489-500.

2. Cao, D.; Wang, L.; Wang, Y. Endogenous fluctuations induced by nonlinear pollution accumulation in an OLG economy and the bifurcation control. Econ. Model. 2011, 28, 2528-2531.

3. Seegmuller, T.; Verchere, A. Pollution as a source of endogenous fluctuations and periodic welfare inequality in OLG economies. Econ. Lett. 2004, 84, 363-369.

4. Schumacher, I.; Zou, B. Pollution perception: A challenge for intergenerational equity. J. Environ. Econ. Manag. 2008, 55, 296-309.

5. Gallaway, T. On light pollution, passive pleasures, and the instrumental value of beauty. J. Econ. Issues 2010, 44, 71-88.

6. Nordhaus, W. A Question of Balance: Weighing the Options on Global Warming Policies; Yale University Press: New Haven, CT, USA, 2008; Volume 9, pp. 146-147. 
7. El Ouardighi, F.; Benchekroun, H.; Grass, D. Controlling pollution and environmental absorption capacity. Ann. Oper. Res. 2014, 220, 111-133.

8. Zemel, A. Precaution under mixed uncertainty: Implications for environmental management. Resour. Energy Econ. 2012, 34, 188-197.

9. Canadell, J.G.; Le Quéré, C.; Raupach, M.R.; Field, C.B.; Buitenhuis, E.T.; Ciais, P.; Conway, T.J.; Gillett, N.P.; Houghton, R.A.; Marland, G. Contributions to accelerating atmospheric $\mathrm{CO}_{2}$ growth from economic activity, carbon intensity, and efficiency of natural sinks. Proc. Natl. Acad. Sci. USA 2007, 104, 18866-18870.

10. Sun, Y.W.; Liu, C.; Chan, K.L.; Xie, P.H.; Liu, W.Q.; Zeng, Y.; Wang, S.M.; Huang, S.H.; Chen, J.; Wang, Y.P.; et al. Stack emission monitoring using non-dispersive infrared spectroscopy with an optimized nonlinear absorption cross interference correction algorithm. Atmos. Meas. Tech. 2013, 6, 1993-2005.

11. Endo, S.; Grathwohl, P.; Haderlein, S.B.; Schmidt, T.C. Effects of native organic material and water on sorption reference diesel soot. Environ. Sci. Technol. 2009, 43, 3187-3193.

12. Xepapadeas, A. Economic growth and the environment. In Handbook of Environmental Economics; Maler, K.G., Vincent, J.R., Eds.; Elsevier: North Holland, The Netherlands, 2005; pp. 1219-1271.

13. Gutierres, M.J. Dynamic inefficiency in an overlapping generation economy with pollution and health costs. J. Public Econ. Theory 2008, 10, 563-594.

14. Hofer, C.; Cantor, D.E.; Dai, J. The competitive determinants of a firm's environmental management activities: Evidence from US manufacturing industries. J. Oper. Manag. 2012, 30, 69-84.

15. Ang, J. B. Economic development, pollutant emissions and energy consumption in Malaysia. J. Policy Model. 2008, 30, 271-278.

16. Poumanyvong, P.; Kaneko, S. Does urbanization lead to less energy use and lower $\mathrm{CO}_{2}$ emissions? A cross-country analysis. Ecol. Econ. 2010, 70, 434-444.

17. Duarte, R.; Pinilla, V.; Serrano, A. Is there an environmental Kuznets curve for water use? A panel smooth transition regression approach. Econ. Model. 2013, 31, 518-527.

18. Heijdra, B.J.; Heijnen, P.; Kindermann, F. Optimal pollution taxation and abatement when leisure and environmental quality are complements. De Econ. 2015, 163, 95-122.

19. Dam, L. Socially responsible investment in an environmental overlapping generations model. Resour. Energy Econ. 2011, 33, 1015-1027.

20. Du, L.; Hanley, A.; Wei, C. Marginal abatement costs of carbon dioxide emissions in China: A parametric analysis. Environ. Resour. Econ. 2015, 61, 191-216.

21. Chen, C.C. Assessing the pollutant abatement cost of greenhouse gas emission regulation: A case study of Taiwan's freeway bus service industry. Environ. Resour. Econ. 2015, 61, 477-495.

22. Cazzavillan, G.; Lloyd-Braga, T.; Pintus, P.A. Multiple steady states and endogenous fluctuations with increasing returns to scale in production. J. Econ. Theory 1998, 80, 60-107.

23. Arrow, K.; Bolin, B.; Costanza, R.; Dasgupta, P.; Folke, C.; Holling, C.S.; Jansson, B.O.; Levin, S.; Mäler, K.G.; Perrings, C.; et al. Economic growth, carrying capacity, and the environment. Ecol. Appl. 1996, 6, 13-15.

(C) 2017 by the authors; licensee MDPI, Basel, Switzerland. This article is an open access article distributed under the terms and conditions of the Creative Commons Attribution (CC BY) license (http:/ / creativecommons.org/licenses/by/4.0/). 